\title{
Alcohol is not Safe even at Light Amounts
}

\author{
Aslı Ceren Tahan ${ }^{1}$, Veysel Tahan ${ }^{2}$ \\ ${ }^{1}$ College of Science, University of Iowa, Iowa City, Iowa, United States \\ ${ }^{2}$ Department of Gastroenterology, University of Iowa Hospitals and Clinics, Iowa City, Iowa, United States
}

There is undeniable evidence that alcohol is harmful to health. An increasing concern for alcohol users is underestimating or ignoring its health effects. Some justify their alcohol use by stating that a few drinks may even be good for the health by disregarding a possible future alcohol addiction and dependence problems, while for others it serves as a social gathering necessity. Is alcohol good, bad or ugly?

Many studies have shown that moderate to high alcohol intake significantly increases the risk of developing cancers. The National Institute of Health released a warning about the increased risk of cancer for heavy drinkers. Alcohol can have a direct carcinogenic effect in gastrointestinal cancers and can also have indirect effects via the overexpression of oncogenes in cells, thus triggering the development of cancer. In addition, a co-carcinogenic effect is seen by boosting the carcinogenic properties of other chemicals. Alcohol reduces blood levels of vitamins $\mathrm{A}$ and $\mathrm{E}$, zinc, iron and some $\mathrm{B}$ vitamins, including folate and thiamin, accounting for the increased risk of cancer. Alcohol suppresses the immune system and makes alcoholics more susceptible to developing cancer. Most of the clinical data examined moderate to high alcohol intake studies. Therefore, there is no consensus on a safe level of alcohol use $(1,2)$.

The risks associated with alcohol use cannot be limited to only cancer. However, it is important to note that the alcohol industry lost a competition recently. Bagnardi et al. (3) recently stayed away from all negative impulses and reported a meta-analysis about light alcohol drinking and cancer. Alcohol consumption increases the risk of oral cavity, pharynx, esophagus, larynx, liver, breast, and colorectal cancer. The level of alcohol consumption was shown to increase the risk of alcohol-related cancer. Prior to this study, most of the data were derived from studies of moderate to high alcohol intake. For the first time, the researchers evaluated the association between light alcohol drinking (up to 1 drink daily) and cancers by evaluating 13,814 non-unique papers identified through a literature search; in total, 222 unique papers were included in the meta-analysis, comprising 92,000 light drinkers and 60,000 non-drinkers with cancer. Even light drinking was associated with the risk of oropharyngeal cancer, esophageal squamous cell cancer and female breast cancer. No absolute safe level of alcohol intake can be endorsed. This study is important because it was published against the alcohol industry and their enormous power against public health (3).

Can these study results break the alcohol industry's defense and its social place to develop a fear of cancer or other alcohol-related diseases, which may also prevent the majority of people from enjoying even an occasional drink? We are not sure, but hopefully it will be beneficial to have people rethink this toxin and fight against alcohol abuse and dependence.

Ethics Committee Approval: N/A.

Informed Consent: N/A.

Peer-review: Externally peer-reviewed.

Author contributions: Concept - V.T, A.C.T.; Design - V.T, A.C.T.; Supervision - V.T, A.C.T.; Resource - V.T., A.C.T.; Materials - V.T, A.C.T.; Data Collection \&/or Processing - V.T, A.C.T.; Analysis \&/or Interpretation - V.T, A.C.T.; Literature Search - V.T, A.C.T.; Writing - V.T, A.C.T.; Critical Reviews - V.T.

Conflict of Interest: No conflict of interest was declared by the authors.

Financial Disclosure: The authors declared that this study has received no financial support.

\section{REFERENCES}

1. Boffetta P, Hashibe M, La Vecchia C, Zatonski W, Rehm J. The burden of cancer attributable to alcohol drinking. Int J Cancer 2006;119:884-7. [CrossRef]

2. Pöschl G, Seitz HK. Alcohol and cancer. Alcohol Alcohol 2004;39:155-65. [CrossRef]

3. Bagnardi V, Rota M, Botteri E, Tramacere I, Islami F, Fedirko $\mathrm{V}$, et al. Light alcohol drinking and cancer: a meta-analysis. Ann Oncol 2013;24:301-8. [CrossRef]

Address for Correspondence: Dr. Veysel Tahan, Department of Gastroenterology, University of Iowa Hospitals and Clinics, Iowa City, Iowa, United States Phone: 0014122457163 e-mail: veysel-tahan@uiowa.edu, veyseltahan@yahoo.com Received: 09.11.2014 Accepted: 28.12.2014 • DOI: 10.5152/balkanmedj.2015.150853

Available at www.balkanmedicaljournal.org 